\title{
Thói quen phát triển chuyên môn của giáo viên ở các trường phổ thông Việt Nam
}

\section{Hoàng Anh Đức*, Tạ Thu Hằng*, Tạ Ngọc Thúy*}

\author{
*Trung tâm Nghiên cứu và Phát triển Giáo dục EdLab Asia, Hà Nội, Việt Nam
}

\section{Tóm tắt:}

Nguồn lực và chất lượng giáo viên là một trong những mối quan tâm thiết yếu để phát triển giáo dục bền vững. Thông qua phân tích bộ dữ liệu "Khảo sát thói quen phát triển chuyên môn giáo viên các truờng phổ thông ở Việt Nam năm 2019” với 464 quan sát về thói quen học tập của giáo viên phổ thông từ các trường công lập và tư thục trên cả nước, chúng tôi thực hiện nghiên cứu phân tích thói quen phát triển chuyên môn của giáo viên. Đây là nghiên cứu đầu tiên trong dự án nghiên cứu về năng lực chuyên giáo viên phổ thông Việt Nam giai đoạn 2020 - 2025 của Trung tâm nghiên cứu và Phát triển Giáo dục EdLab Asia. Từ kết quả nghiên cứu đầu tiên này, dự án tiếp tục đối sánh sự khác biệt trong thói quen phát triển chuyên môn giáo viên phổ thông tại các hệ thống trường công lập và tư thục trong các năm tiếp theo. Bằng cách phân tích dữ liệu về số giờ tham gia hoạt động phát triển chuyên môn của giáo viên ở từng loại hình trường, nghiên cứu chỉ ra sự khác biệt về thói quen học tập của giáo viên các cấp phổ thông với từng loại hình nhà trường. Nghiên cứu cũng chỉ ra rằng hoạt động phát triển chuyên môn giáo viên của trường tư thục tốt hơn trường công lập. Kết quả của nghiên cứu là gợi ý cho các nhà hoạch định chính sách, các nhà quản lý giáo dục tại các cơ sở giáo dục phổ thông, không kể công-tư tham chiếu và điều chỉnh các kế hoạch, chương trình phát triển chuyên môn giáo viên.

Từ khoá: Phát triển chuyên môn giáo viên, Giáo dục phổ thông, Việt Nam, Công lập, Tư thục

\section{Tổng quan}

Kể từ những năm 1990, khi đời sống bắt đầu có những bước chuyển mình mạnh mẽ trong công cuộc phát triển kinh tế và xã hội, việc liên tục trau dồi và bồi dưỡng khả năng chuyên môn để đáp ứng nhu cầu của thời đại được cho là vấn đề được quan tâm hàng đầu (Beijaard \& c.s., 2007), đặc biệt là trong lĩnh vực giáo dục (Feiman-Nemser, 2001). Các nhà nghiên cứu đưa ra rất nhiều định nghĩa khác nhau về phát triển chuyên môn cho giáo viên. Ví dụ, Darling và McLaughlin (1995) định nghĩa việc phát triển chuyên môn giáo viên là quá trình thúc đẩy sự hiểu biết của giáo viên đối với việc dạy và học cũng như tạo điều kiện để giáo viên có cơ hội hiểu rõ học sinh của mình. McLaughlin (2001) cho rằng việc xây dựng các chương trình phát triển giáo viên là chiến lược quan trọng để nâng cao thành tích học tập của học sinh. Một định nghĩa khác được Day (1999) đưa ra rằng phát triển chuyên môn giáo viên là các hoạt động được thiết kế để giáo viên tham gia học hỏi, nhìn nhận, đổi mới và mở rộng những kiến thức và kỹ năng mới. Có thể thấy, việc phát triển chuyên môn giáo của giáo viên được định nghĩa từ những góc nhìn khác nhau, song vẫn cùng đặt ra sứ mệnh chung: không ngừng cập nhật, sửa đổi và tiến bộ song song với tốc độ thay đổi nhanh chóng của thời cuộc (Cordingley \& c.s., 2005).

Những hoạt động phát triển chuyên môn giáo viên dù được đánh giá cao về tầm quan trọng cũng như mức độ ảnh hưởng đến chất lượng nguồn nhân lực, kết quả học tập của học sinh, nhưng xét về cách tổ chức, nhiều giáo viên nhận thấy chúng chưa thực sự có hiệu quả (Webster-Wright, 2009). Tài liệu chuẩn bị cho những hoạt động phát triển chuyên môn không gắn liền với bối cảnh thực tế, hay nói cách khác, chưa giải quyết được những vấn đề mà giáo viên đang gặp phải. (Kennedy, 2014). Thời gian cho những hoạt động này tương đối ngắn và thường không đủ để giáo viên kịp chiêm nghiệm lại những gì mình đã làm, bàn luận những gì đang làm và chia sẻ những mong muốn sẽ làm được trong tương lai (Lessing \& De Witt, 2007). Nhiều trường học cũng chưa thực sự dành nhiều tâm huyết cho việc phát triển giáo viên nên văn hóa học tập và trau dồi thường xuyên của giáo viên còn yếu kém (Forte \& Flores, 2014). Do đó, trong bài nghiên 
cứu này, chúng tôi tập trung phân tích thói quen phát triển chuyên môn giáo viên giữa hai loại hình trường học công lập và tư thục.

\section{Cơ sở lý thuyết}

\subsection{Vai trò của việc phát triển chuyên môn giáo viên (Teacher Continuing Professional Development - CPD)}

Cùng với chương trình và giáo trình, năng lực giáo viên đóng vai trò quan trọng trong việc phát triển các hệ thống giáo dục, ở cả mức độ quốc gia (Dadds, 1997; Sparks và Hirsh, 2000), địa phương (Sparks \& Loucks-Horsley, 1990) và nhà trường (Nyunt \& Ye, 2019). Từ đầu những năm 90 của thế kỷ XX, phát triển chuyên môn giáo viên đã trở thành một trong những đề tài được quan tâm bởi giới nghiên cứu Đông (Shimahara, 1998; Yip, 1998; Walker, 1996) và Tây (Corconan, 1995; OECD, 1998). Ở mỗi cấp độ, quốc gia, địa phương và nhà trường, hoạt động phát triển chuyên môn giáo viên được tiếp cận theo nhiều cách khác nhau (Shallcrost \& c.s., 2000).

Ở cấp độ quốc gia, bất kể hệ thống giáo dục mà chương trình được quản trị tập trung (centralizedcurriculum) hay quản trị phân tán (decentralized-curriculum), các nhà nghiên cứu đều chú trọng phân tích các đặc điểm cấu trúc của chương trình phát triển chuyên môn, bao gồm: loại hình, thời lượng, và sự tham gia của đội ngũ giáo viên (Desimone \& Park, 2017; Garet và c.s., 2001; Nyunt \& Ye, 2019). Xây dựng chương trình phát triển chuyên môn giáo viên dựa trên ba đặc điểm cốt lõi này là quá trình cần có được sự đầu tư tổng thể và dài hạn, với nguồn lực tài chính, cơ chế giám sát và hệ thống đánh giá xuyên suốt cả quá trình (Villegas-Reimers, 2003).

Hình thức hoạt động phát triển chuyên môn giáo viên là yếu tố quan trọng, quyết định hiệu quả phát triển chuyên môn của giáo viên (Darling-Hammond, 1997; Garet \& c.s., 2001; Villegas-Reimers, 2003). Những phương thức phát triển chuyên môn giáo viên không được hưởng ứng nhiều nhất là các hội nghị, hội thảo, các khóa học diễn ra bên ngoài nhà trường, vào dịp nghỉ hè, cuối tuần hay cuối giờ học (Louckes-Horsley \& c.s., 1998). Sở dĩ, những loại hình phát triển chuyên môn giáo viên truyền thống này không hiệu quả do không đáp ứng đủ thời gian cho các hoạt động, không đảm bảo nội dung cần thiết giúp giáo viên bổ sung kiến thức cũng như không có được những thay đổi tích cực trong hoạt động giảng dạy (Louckes-Horsley \& c.s., 1998; Garet \& c.s., 2001). Do đó, các nhà nghiên cứu giáo dục ngày càng quan tâm nhiều hơn đến hình thức phát triển chuyên môn giáo viên cải tiến, đó là xây dựng thành những cộng đồng học tập, trong đó các nhóm cố vấn, huấn luyện, những giáo viên kỳ cựu đóng vai trò là những người quan sát, huấn luyện đồng thời cho những giáo viên mới (Garet \& c.s., 2001; Broad \& Evans, 2006). Hình thức phát triển chuyên môn giáo viên cải tiến được đánh giá cao bởi tính gắn kết cao với các hoạt động hàng ngày của giáo viên và người học cũng như trở thành một phần trong công việc hàng ngày của giáo viên (Sparks \& Hirsh, 2000; Imants và van Veen, 2010).

Phát triển chuyên môn giáo viên hiệu quả khi có lượng thời gian phù hợp đủ để thực hành, thực hiện và hoàn thiện các chiến lược mới, tạo điều kiện cho những thay đổi trong thực tiễn của họ (Darling \& c.s., 2017). Thời lượng phát triển chuyên môn giáo viên phù hợp mang lại cho giáo viên cơ hội thảo luận sâu về nội dung, các tình huống và chiến lược sư phạm, cơ hội thực hành những điều mới được học vào thực tiễn hoạt động giảng dạy hay tiếp nhận những ý kiến phản hồi để điều chỉnh, thay đổi hoạt động (Abdal-Haqq, 1996; Garet \& c.s., 2001). Hội đồng Phát triển chuyên môn Quốc gia Hoa Kỳ (The National Staff Development Council - NSDC), hiệp hội phi lợi nhuận về phát triển nhân sự và cải tiến trường học khuyến nghị, nên dành ít nhất $25 \%$ thời gian của giáo viên cho phát triển chuyên môn (Sparks \& Hirsh, 2000).

Hoạt động phát triển chuyên môn giáo viên đạt kết quả tốt hơn khi có sự tham gia của tập thể nhóm các giáo viên cùng trường, cùng bộ phận, cùng cấp học, khối lớp (Garet \& c.s., 2001; OECD, 2013; Scotchmer, 
2005; Sparks, 2000). Từ 2009 đến 2011, qua quá trình lựa chọn và nghiên cứu 31 bài báo về phát triển chuyên môn giáo viên, Postholm (2012) cho rằng, mức độ tương tác của tập thể giáo viên trong chính công việc của mình cũng được cho là yếu tố quyết định chất lượng phát triển chuyên môn của giáo viên. Phát triển chuyên môn theo nhóm giáo viên cùng trường sẽ giúp giáo viên có nhiều cơ hội thảo luận, dễ dàng chia sẻ và hỗ trợ chuyên môn cho nhau, đồng thời giúp duy trì sự ổn định của hoạt động này khi có sự thay đổi nhân sự (Garet \& c.s., 2001). Phát triển chuyên môn theo nhóm giáo viên cùng trường cũng được cho là cách tốt nhất xây dựng văn hóa nhà trường, văn hóa chia sẻ và văn hóa học tập (Cochran-Smith \& c.s., 2001).

Ở cấp độ địa phương, hoạt động phát triển chuyên môn giáo viên được tiếp cận tương đối linh hoạt (Jaquith \& c.s., 2010). Ví dụ, các tiểu bang Colorado, Missouri, New Jersey và Vermont của Mỹ đánh giá hoạt động phát triển chuyên môn giáo viên dựa trên mức độ tham gia của giáo viên, sự uy tín của các tài liệu và kết quả cải thiện thành tích học tập của học sinh. Bang Florida xây dựng mô hình phát triển chuyên môn giáo viên toàn tiểu bang dựa trên nghiên cứu bài học (Akiba \& Wilkinson, 2016). Các thành phố ở Myanmar quan tâm đến mối liên hệ giữa nhận thức và sự hài lòng của giáo viên trong công việc với hoạt động phát triển chuyên môn (Nyunt \& Ye, 2019). Năm quận ở Uganda quan tâm đến nhận thức của giáo viên về phát triển chuyên môn, các phương pháp thực hiện cũng như các khó khăn mà giáo viên đang gặp phải trong quá trình dạy học và tham gia các chương trình phát triển chuyên môn (Kagoda \& c.s., 2014). Kết quả nghiên cứu tại năm quận cho thấy các giáo viên nữ đang gặp phải tương đối nhiều khó khăn cản trở các hoạt động phát triển chuyên môn. Nhiều giáo viên nữ không thể sắp xếp và cân bằng được khối lượng thời gian dành cho công việc và gia đình, mức thu nhập không ổn định, không có đầy đủ phương tiện tiếp cận các hoạt động phát triển chuyên môn và trong đó rào cản lớn nhất là họ không có sự hỗ trợ từ nhà trường ngay cả khi họ có ý định muốn nâng cao khả năng chuyên môn của bản thân.

Các nghiên cứu về phát triển chuyên môn ở cấp độ nhà trường tập trung chủ yếu vào các yếu tố ảnh hưởng đến hoạt động phát triển chuyên môn giáo viên. Hustler (2003) chia yếu tố ảnh hưởng đến giáo viên khi tham gia phát triển chuyên môn thành ba nhóm: yếu tố cá nhân (thái độ chuyên nghiệp, đánh giá tính khả thi, đánh giá ý nghĩa, sự quá tải và thành tựu cá nhân), yếu tố nhiệm vụ (áp lực công việc, nhu cầu cảm xúc, tính đa dạng của công việc, sự tự chủ, sự tham gia) và yếu tố môi trường làm việc (sự hỗ trợ của quản lý, hỗ trợ từ đồng nghiệp, hỗ trợ học tập có chủ ý). Lee (2005) phân chia các yếu tố ảnh hưởng đến phát triển chuyên môn của giáo viên thành hai nhóm, đó là yếu tố tạo thuận lợi và yếu tố kìm hãm sự phát triển.

Bất kể các hoạt động phát triển chuyên môn được hoạch định và triển khai ở cấp độ nào, những yếu tố như động lực nội sinh từ giáo viên, động lực ngoại sinh từ đội ngũ quản lý, đồng nghiệp và thói quen học tập, năng lực cá nhân, thời gian, kỹ năng sử dụng công nghệ, tài chính cũng đóng một vai trò vô cùng quan trọng (Durksen \& c.s., 2017). Bên cạnh đó, phát triển chuyên môn giáo viên cũng chịu ảnh hưởng từ cấu trúc, loại hình trường học, môi trường và văn hóa học đường (Ryan \& Deci, 2000; Scribner, 1999).

\subsection{Phát triển chuyên môn giáo viên phổ thông ở Việt Nam}

Phát triển chuyên môn giáo viên được coi là yếu tố then chốt để thực hiện thành công đổi mới căn bản, toàn diện giáo dục. Bộ Giáo dục và Đào tạo (Bộ GD\&ĐT) đã xây dựng đề án "Đào tạo và Bồi dưỡng đội ngũ Nhà giáo và Cán bộ quản lý cơ sở giáo dục phổ thông đáp ứng yêu cầu đổi mới căn bản, toàn diện giáo dục phổ thông giai đoạn 2016-2020, định hướng đến năm 2025" - National Teacher Education Program (NTEP). Chương trình NTEP là một chiến lược toàn diện nhằm đào tạo chính quy đối với giáo viên mới, đào tạo lại với một số giáo viên không đạt yêu cầu, bồi dưỡng và phát triển chuyên môn thường xuyên cho giáo viên để có thể đủ năng lực đáp ứng chương trình giáo dục phổ thông mới. Trong khuôn khổ triển khai chương trình NTEP, Chính phủ và Ngân hàng Thế giới đã thực hiện đề án "Chương trình Phát triển các trường sư phạm để nâng cao năng lực đội ngũ giáo viên và cán bộ quản lý cơ sở giáo dục phổ thông” - Enhancing 
Teacher Education Program (ETEP). Hoạt động phát triển chuyên môn giáo viên trong khuôn khổ Chương trình ETEP (2016-2019) đã mang đến sự thay đồi về tư duy quản trị của các trường sư phạm, đồng bộ nhu cầu thực tế và các tiêu chuẩn nghề nghiệp (Bộ GD\&ĐT, 2019). Đây là chương trình được xây dựng dựa trên mục tiêu phát triển các trường đại học sư phạm, tăng cường chất lượng đội ngũ giáo viên, cán bộ quản lý cơ sở giáo dục phổ thông, thông qua phát triển nghề nghiệp theo nhu cầu thực tiễn và đáp ứng nhu cầu đổi mới căn bản và toàn diện giáo dục.

Bên cạnh các chương trình phát triển chuyên môn giáo viên của Bộ GD\&ĐT, một số tổ chức, doanh nghiệp nước ngoài cũng góp phần không nhỏ vào các hoạt động phát triển chuyên môn cho giáo viên. Chương trình Intel Tech đã đào tạo 78,000 giáo viên cách kết hợp công nghệ vào bài giảng để nâng cao kỹ năng giải quyết vấn đề, khả năng suy đoán và tinh thần làm việc nhóm của học sinh (Minh, 2020). Microsoft đã xây dựng cộng đồng giáo dục giúp cho giáo viên có cơ hội tiếp cận với các nguồn lực, tạo môi trường tương tác, trao đổi, học hỏi và có cơ hội phát triển chuyên môn. Thông qua các ứng dụng như Office 365 Education, OneDrive và Surface cùng các thiết bị và phụ kiện của Windows 10 , giáo viên đã được hỗ trợ đáng kể trong quá trình dạy và học, môi trường học tập 1 kèm 1 Pearson. Đây là một trong những tổ chức cung cấp các giải pháp giáo dục lớn nhất thế giới, đã và đang đào tạo cũng như tập huấn cho các giáo viên biết sử dụng và khai thác các bài giảng số, cập nhật phương pháp giảng dạy tiên tiến nhất và sử dụng công nghệ trong giảng dạy. Một chương trình khác là National Geographic Learning cũng được đánh giá cao trên thế giới về đào tạo và nghiên cứu giáo dục cũng đang tham gia vào bồi dưỡng giáo viên, phát triển chương trình dạy học tiếng Anh cùng Bộ GD\&ĐT ở "Đề án Ngoại ngữ quốc gia 2020".

Hoạt động phát triển chuyên môn giáo viên ở trường công lập và trường tư thục có sự khác biệt do đặc thù quyền hạn và nhiệm vụ của mỗi loại hình trường. Ở các trường công lập, nhà trường có trách nhiệm giải trình với xã hội, người học, cơ quan quản lý và bảo đảm việc tham gia của người học, gia đình và xã hội; tổ chức bộ máy nhân sự và tài chính theo quy chế dân chủ trong nhà trường theo quy định của điều 60 Luật Giáo dục (Bộ GD\&ĐT). Theo đó, hoạt động phát triển chuyên môn giáo viên ở trường công lập được thực hiện theo chỉ đạo, kế hoạch của Sở Giáo dục, Phòng Giáo dục. Tại Việt Nam hiện nay có ba loại hình trường tư thục chính: trường tư thục quốc tế, trường tư thục song ngữ và trường tư thục với chương trình thông thường.Với các loại hình trường tư thục, hiệu trưởng và Hội đồng quản trị trường học chủ động đưa ra quyết định liên quan đến các hoạt động phát triển chuyên môn giáo viên của trường mình, dựa trên nhu cầu của giáo viên, định hướng phát triển, các giai đoạn phát triển và định mức tài chính của từng trường.

Giữa các trường tư thục, hoạt động phát triển chuyên môn giáo viên cũng rất khác biệt. Cuối những năm 90 của thế kỷ $X X$, những trường học tư thục ra đời với vai trò giải quyết được nhu cầu được học của học sinh, hay nói cách khác là mô hình thay thế cho các trường công lập nên giáo dục vẫn đặt nặng điểm số. Do đó việc phát triển năng lực giáo viên chưa thực sự được chú trọng, phần lớn các hoạt động bồi dưỡng giáo viên tại các trường này đều chủ yếu nhằm bồi dưỡng tại các trường học này phần lớn nhằm đáp ứng chuẩn nghề nghiệp dưới sự chỉ đạo của hiệu trưởng. Như vậy, có thể thấy trong giai đoạn trước, giáo dục tư thục như một lựa chọn thay thế cho các học sinh không vào được trường công lập. Tuy nhiên, khoảng sau những năm 2010, vị thế của các trường tư thục được cải thiện, cạnh tranh trực tiếp với trường công lập và chú trọng nhiều hơn đến việc phát triển toàn diện kỹ năng cho học sinh thay vì chỉ xem nặng điểm số. Cách tiếp cận này được cho là đã phần nào thúc đẩy phát triển chuyên môn giáo viên (Lộc, 2010).

Trong những năm gần đây tại Việt Nam, tầm quan trọng của các hoạt động phát triển chuyên môn giáo viên được Bộ GD\&ĐT cũng như các nhà nghiên cứu được chú trọng nhiều hơn (Vũ, 2016; Tuyết, 2017). Năm 2015, Bộ GD\&ĐT đã đưa ra phương án chỉ đạo về thay đổi và đổi mới phương án dạy và học (Lê \& c.s., 2020). Phương án này ra đời nhằm tiến tới phù hợp với xu thế phát triển giáo dục và bền vững theo bốn tiêu chí: toàn diện, công bằng, chất lượng và học tập suốt đời (Kiều \& c.s., 2016; Stabback, 2016). Một số nhà nghiên cứu cho rằng ngay từ khi vẫn còn ngồi trên ghế giảng đường đại học, các giáo viên tương lai 
cần nhận ra tầm quan trọng của việc liên tục trau dồi và phát triển chuyên môn (Nghĩa và Tài, 2017). Dạy học là một ngành nghề đặc biệt vì đào tạo ra con người, nhất là trong bối cảnh xã hội không ngừng đổi thay từng ngày (Lê \& c.s., 2020). Bên cạnh đó, việc thiết kế chương trình đào tạo giáo viên còn khô cứng, không linh hoạt và không sát với bối cảnh thực đã hình thành cho giáo viên thói quen ngại thay đổi và không quen với những chương trình phát triển chuyên môn sau khi đã vào nghề (Hoàng \&Ninh, 2017).

\subsection{Phát triển chuyên môn giáo viên tại trường công lập và trường tư thục}

Khi nhắc đến sự khác nhau trong hệ thống giáo dục công lập và tư thục, không thể không nhắc đến hai mô hình quản trị phân hóa và tập trung. Tuy nhiên, tại Việt Nam, rất khó để có thể so sánh sự khác biệt giữa hai hệ thống giáo dục công-tư nếu chỉ thông qua mô hình quản trị. Khác với một số quốc gia trên thế giới, nền giáo dục Việt Nam là sự gioa thoa và thậm chí là nhập nhằng giữa cả hai mô hình quản trị (Hoàng \& c.s., 2020). Mặc dù tiền thân của nền giáo dục Việt Nam là giáo dục tập trung do chịu sự ảnh hưởng của Nho giáo nhưng hiện nay dưới sự tác động của khoa học công nghệ, nền giáo dục Việt Nam không tránh khỏi sự thay đổi và dịch chuyển đến mô hình quản trị phân hóa. Sự dịch chuyển này đã kéo theo sự ra đời của các trường tư thục ở Việt Nam, phục vụ cho nhu cầu Hiện nay, các trường tư thục phổ thông tại Việt Nam được chia làm ba loại hình chính: trường tư thục quốc tế, trường tư thục song ngữ và trường tư thục với chương trình thông thường. Tuy rằng những loại hình trường tư thục này được ra đời vì nhu cầu người học ngày một đa dạng nhưng vẫn bị giới hạn bởi các chương trình của Bộ. Ví dụ, một mặt các trường tư thục vẫn cho học sinh học theo chương trình cơ bản đại chúng nói chung, mặt khác vẫn áp dụng các chương trình riêng của nhà trường hoặc theo nhu cầu của phụ huynh học sinh.

Bên cạnh sự khác biệt trong mô hình quản trị, yếu tố tài chính giữa hai hệ thống giáo dục công-tư cũng là không giống nhau (Choy, 1997). Trong khi các trường công lập được quản lý và tài trợ bởi chính quyền địa phương, tiểu bang hoặc quốc gia thì nguồn tài chính của các trường tư thục chủ yếu đến từ học phí của học sinh, do một công ty tư nhân quản lý và trong đó hội đồng quản trị quyết định mọi vấn đề của nhà trường (Dronkers và Robert, 2003). Thông thường, có rất nhiều lý do chủ quan hoặc khách quan khác nhau khiến nhiều phụ huynh lựa chọn trường tư thục, nhưng một trong số đó hầu như đến từ sự không hài lòng với phương pháp giáo dục tại các trường học công lập (Choy, 1997). Bên cạnh việc trường tư được phụ huynh lựa chọn thay thế trường công, một số trường tư thục được xây dựng chỉ dành cho giới nhà giàu (Cheng \& Delany, 1999). Chính sự khác biệt này dẫn đến tình trạng chênh lệch trong đặc điểm học sinh và thành phần trường học (Dronkers \& Robert, 2003). Học sinh trường tư được cho là có các đặc điểm xã hội tốt hơn học sinh trường công vì các em được hưởng nền tảng gia đình có giáo dục và tài chính tốt ngay từ khi còn nhỏ.

Năm 2009, một nhóm học giả nghiên cứu các trường phổ thông công lập tại Ý nhận thấy rằng giáo viên tại các trường công lập có xu hướng chủ động tham gia vào các hoạt động phát triển chuyên môn mà không phải với mục đích chính là để nâng cao kiến thức và kỹ năng (Kemp \& Productions, 2009). Có rất nhiều giáo viên năng nổ và nhiệt tình với các hoạt động phát triển chuyên môn vì mong muốn có được hoặc thay đổi vị trí cao hơn trong công việc thay vì chỉ dạy học. Điều này tỷ lệ thuận với một vài giải thích cho rằng giáo viên trường công không hứng thú với các hoạt động phát triển chuyên môn, tham gia một cách hời hợt khi không nhận thấy lợi ích tương đồng nào từ chúng (Peretomode \& Dinzei, 2019). Geller \& c.s. (2006) cho rằng giáo viên tại các trường công lập không thể hiện thái độ tích cực với những hoạt động phát triển chuyên môn một phần là do sự ảnh hưởng trong môi trường làm việc quan liêu, an toàn và không cởi mở như hệ thống giáo dục tư thục. Những giáo viên dạy tại các cơ sở giáo dục công lập cũng không có tính cạnh tranh trong công việc cao nên xảy ra tình trạng quá hài lòng với những gì đang có mà không quan tâm về việc thay đổi những phương pháp dạy học không hiệu quả hay xây dựng và trau dồi những kỹ năng còn thiếu. Một số giáo viên công lập có năng lực đã từ bỏ môi trường làm việc khuôn khổ và cứng nhắc và làm việc tại các trường tư thục khi những trường này đưa ra chính sách có phần hợp lý và trân trọng người tài 
hơn (Green \& c.s., 2008). Hơn nữa, những giáo viên có tâm thế muốn thay đổi cũng bị sụt giảm ý chí khi không có đồng nghiệp nào đồng hành (Urquiola, 2016).

Nhận thức về tầm quan trọng và triển khai hoạt động phát triển chuyên môn ở trường tư thục cao hơn trường công lập (Babanoğlu \& Yardımc1, 2017). Do đặc thù trường tư thục là tổ chức kinh doanh giáo dục vì lợi nhuận, có tính cạnh tranh cao bởi phụ huynh lựa chọn trường tư dựa vào danh tiếng của trường nên điều này thúc đẩy giáo viên tư thục luôn phải đổi mới, trách nhiệm và cập nhật hơn về phương pháp giảng dạy (Babanoğlu \& Yardımc1, 2017; Dronkers \& Robert, 2003). Hơn nữa, trường tư thục tự chủ tài chính và độc lập trong quản trị nên mọi vấn đề của nhà trường do hội đồng quản trị quyết định có tính quyết đoán cao hơn trường công lập (Babanoğlu \& Yardımc1, 2017). Sự tín nhiệm của phụ huynh về khả năng cung cấp dịch vụ của trường tư thục thúc đẩy giáo viên luôn trau dồi, cầu tiến và cải thiện chất lượng (Tooley \& Longfield, 2015; OECD, 2012). Chương trình giảng dạy tại trường tư cũng được cho là có có tính ưu việt, cập nhật và thực tế (Dronkers \& Robert, 2003).

\section{Mô hình nghiên cứu}

Nghiên cứu này tập trung làm rõ sự khác biệt về thói quen phát triển chuyên môn của giáo viên trường công lập và các loại hình trường tư thục tại Việt Nam thông qua tổng số giờ tham gia các hoạt động bồi dưỡng chuyên môn trực tuyến và trực tiếp. So với các yếu tố tác động đến việc tham gia các chương trình phát triển chuyên môn giáo viên như giáo viên phải tự bỏ tiền để tham gia, chi phí chương trình đắt hay nội dung chương trình không bám sát thực tế; việc giáo viên không thể sắp xếp được thời gian hợp lí để tham gia những chương trình này được cho là lí do cản trở hàng đầu (Sellen, 2016).

Để tìm hiểu có hay không sự khác biệt về thói quen phát triển chuyên môn của giáo viên ở các loại hình trường, nghiên cứu dựa trên dữ liệu khảo sát trực tuyến. Những câu hỏi chính được sử dụng trong bảng hỏi được dùng làm công cụ để phân tích sự khác biệt về thói quen, phát triển chuyên môn của giáo viên giữa trường công lập và tư thục trong năm học 2018-2019, đó là:

- Tổng số giờ học trực tuyến của giáo viên ở các loại hình trường;

- Tổng số giờ học trực tiếp của giáo viên ở các loại hình trường;

- Số lượng hoạt động giáo viên tham gia phát triển chuyên môn tự trả phí, hoạt động có thu phí nhưng được tài trợ chi phí và hoạt động miễn phí.

Bộ dữ liệu được thu thập từ ngày 24 tháng 12 năm 2019 đến ngày 24 tháng 3 năm 2020 ở 48 trường phổ thông công lập và tư thục tại Việt Nam để làm rõ sự khác biệt giữa hai loại hình trường công-tư. Bộ dữ liệu thu về 464 phản hồi, bao gồm: 138 giáo viên trường công lập, 144 giáo viên trường tư thục (với chương trình học thông thường), 140 giáo viên trường tư thục song ngữ và 41 giáo viên trường tư thục quốc tế trên khắp cả nước. Mặc dù bộ dữ liệu thu về baog gồm cả giáo viên Việt Nam và giáo viên nước ngoài, nhưng bài nghiên cứu chỉ tập trung làm rõ sự khác biệt trong thói quen phát triển chuyên môn giáo viên giữa các loại hình trường mà không nhấn mạnh vào sự khác biệt giữa các giáo viên. Toàn bộ dữ liệu có thể được truy cập tại kho dữ liệu Mendeley (Hoàng \& c.s., 2020).

\section{Phân tích kết quả}

Nghiên cứu này dùng phần mềm SPSS 20 để phân tích dữ liệu. Dữ liệu thu thập từ khảo sát được tổng hợp, phân tích bằng phương pháp thống kê mô tả và phân tích phương sai (ANOVA).

\subsection{Thống kê mô tả}


Kết quả phân tích sơ bộ cho thấy có sự khác biệt rõ rệt về thói quen phát triển chuyên môn của giáo viên giữa các loại hình trường (Phụ lục 1). Sự khác biệt này thể hiện ở trung bình số giờ giáo viên của các loại hình trường tham gia hoạt động phát triển chuyên môn trực tuyến, trực tiếp khác nhau.

Hình 1: Trung bình số giờ học trục tuyến của giáo viên ở các loại hình truờng

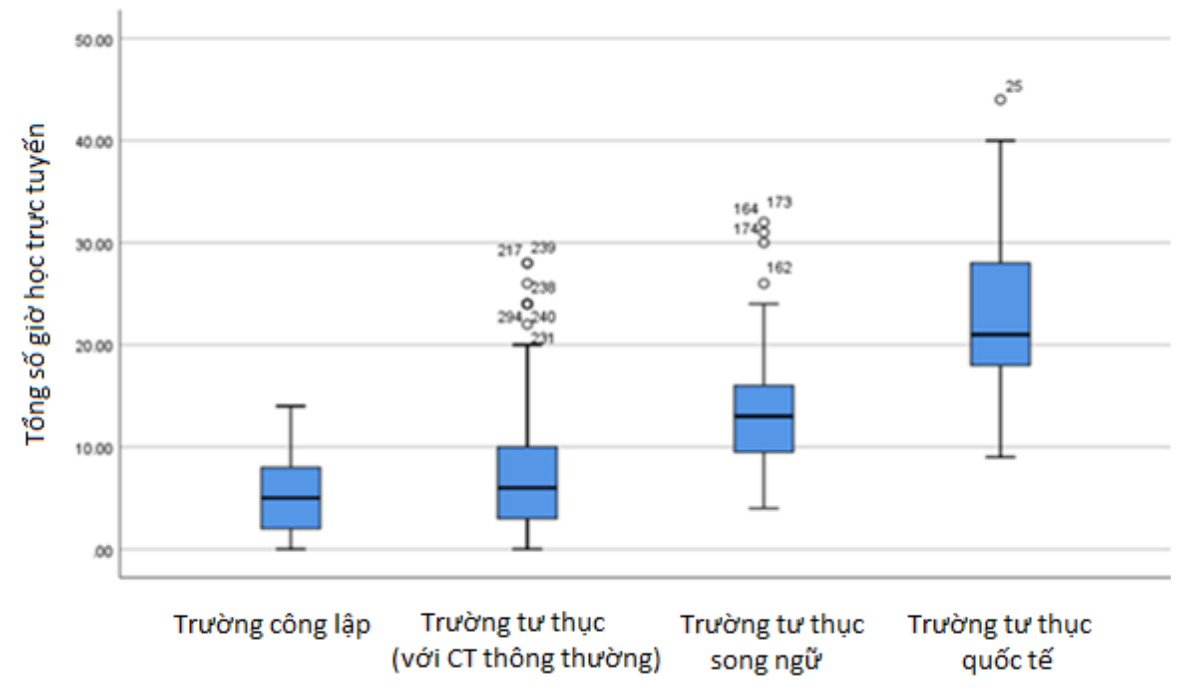

Số giờ trung bình của giáo viên dành cho phát triển chuyên môn theo hình thức trực tuyến ở trường công lập là 5.01 giờ, ở trường tư thục (với chương trình học thông thường) là 7.42 giờ, con số này trường ở tư thục song ngữ là 13.19 giờ, và trường tư thục Quốc tế cao hơn hẳn, với 22.68 giờ.

Hình 2: Trung bình số giờ học trục tiếp của giáo viên ở các loại hình trường

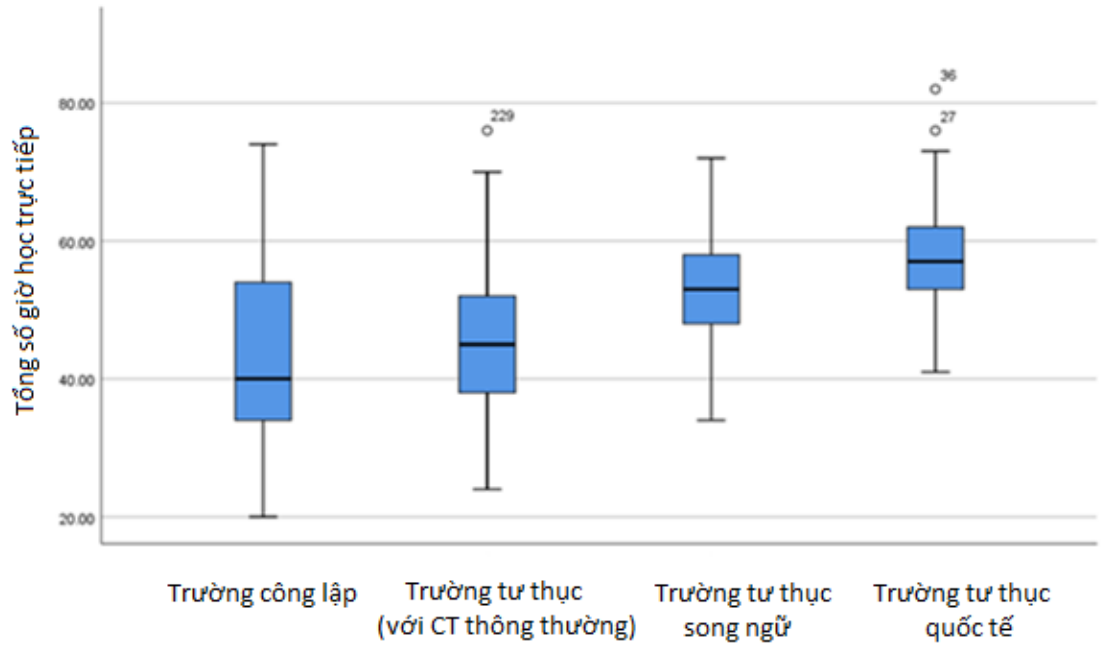

Trung bình số giờ dành cho hoạt động phát triển chuyên môn theo hình thức trực tiếp của giáo viên trường công lập là 43.12 giờ, trường tư thục (với chương trình học thông thường) là 45.08 giờ, trường tư thục song ngữ là 52.71 giờ và trường tư thục Quốc tế là 58.39 giờ. Như vậy, có thể thấy mặc dù giữa các 
loại hình trường số giờ trung bình tham gia giáo viên tham gia trực tiếp các hoạt động phát triển chuyên môn là khác nhau nhưng mức độ chênh lệch là không nhiều so với các hoạt động trực tuyến.

Kết quả thu được cũng cho thấy thói quen phát triển chuyên môn giáo viên ở các loại hình trường khác nhau còn có sự khác biệt do hình thức chi trả cho việc phát triển chuyên môn: giáo viên tự trả phí tham dự (hình 3), hoặc nhà trường chi trả (hình 4).

\section{Hình 3: Số hoạt động phát triển chuyên môn giáo viên tụ trả phí}

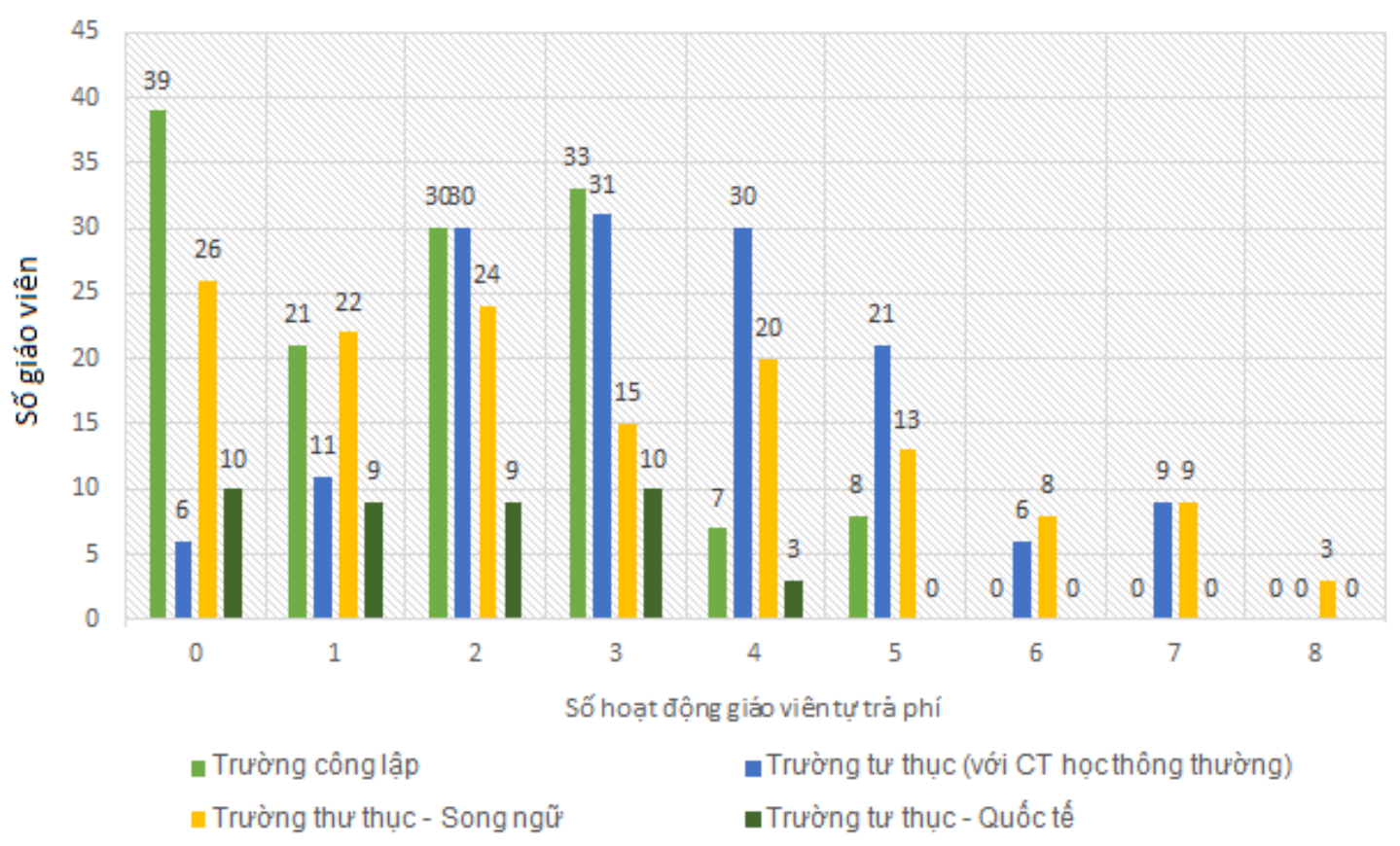

Giáo viên trường công lập tự trả phí cho hoạt động phát triển chuyên môn ở mức phổ biến dưới 5 hoạt động; giáo viên trường tư thục quốc tế chỉ tự trả học phí cao nhất cho 5 hoạt động; trong khi giáo viên trường tư thục (với chương trình học thông thường) và trường tư thục song ngữ sẵn sàng đầu tư nhiều hơn cho phát triển chuyên môn, họ tự trả phí cho từ 7 hoạt động phát triển chuyên môn trở lên. 
Hình 4: Số hoạt động phát triển chuyên môn được nhà truờng hỗ trợ

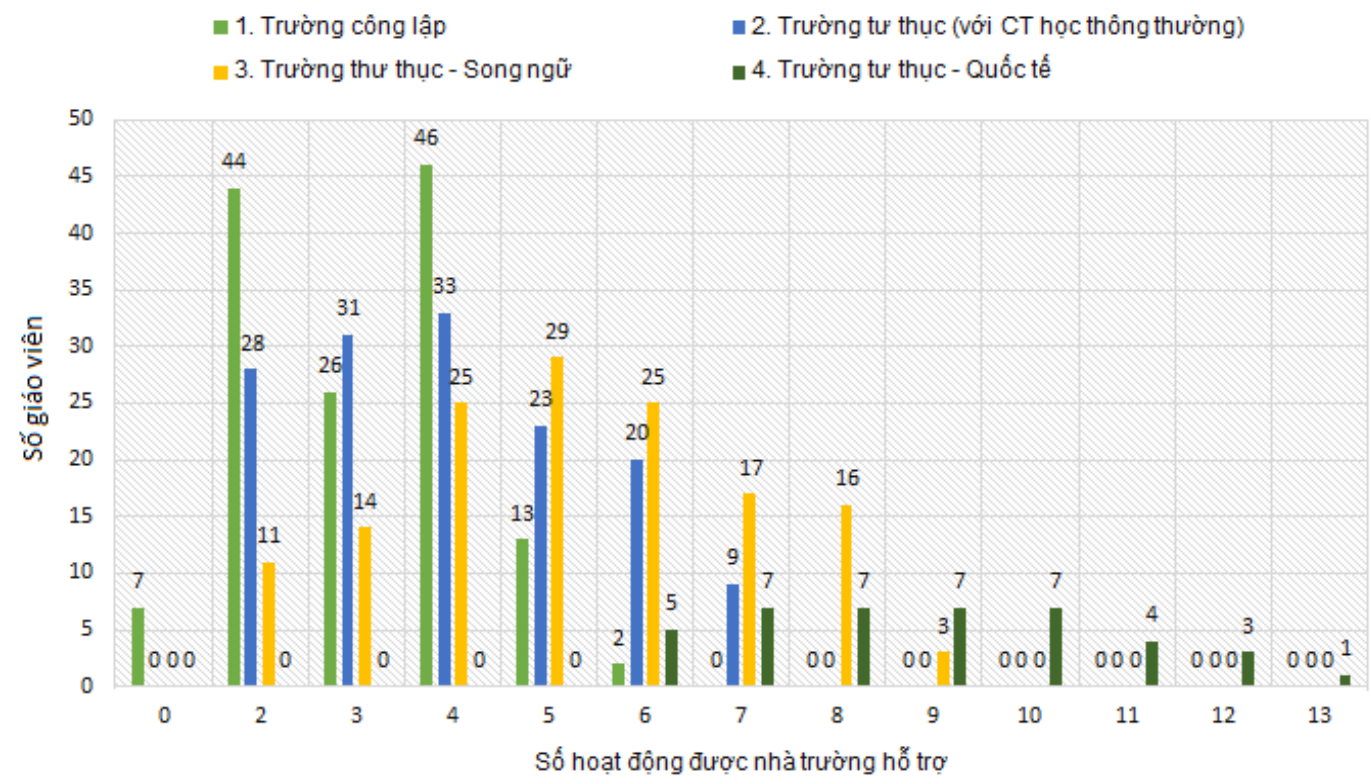

Mức độ hỗ trợ chi phí cho số giờ phát triển chuyên môn của giáo viên ở các loại hình trường cũng thể hiện sự khác biệt thói quen phát triển chuyên môn: trường công lập và tư thục (với chương trình học thông thường) hỗ trợ phổ biến 2 đến 4 hoạt động, trường tư thục song ngữ phổ biến 4 đến 8 hoạt động, trường tư thục quốc tế hô̂ trợ phát triển chuyên môn giáo viên từ ít nhất 6 hoạt động trở lên. Đặc biệt, số lượng trên 10 hoạt động phát triển chuyên môn được tài trợ mỗi năm chỉ được ghi nhận ở các trường quốc tế.

\subsection{Phân tích phương sai}

Để trả lời cho câu hỏi nghiên cứu, phân tích phương sai được thực hiện để tìm ra sự khác biệt giữa số giờ học trực tuyến và trực tiếp nhằm phát triển chuyên môn của giáo viên ở các loại hình trường. Bước đầu tiên trong phân tích phương sai là kiểm định tính đồng nhất của phương sai (homogeneity of variances). Kết quả cho thấy phương sai không đồng nhất nên kiểm định Welch được thực hiện. Tiếp đó, để tìm hiểu rõ hơn sự khác biệt về thói quen phát triển chuyên môn giáo viên giữa các loại hình trường, kiểm định sâu (Post Hoc Test) Tamhane's T2 (Tamhane, 1977) được thực hiện và kết quả được nêu rõ trong Phụ lục 2.

Kết quả kiểm định sâu Tamhane's T2 cho thấy, tất cả các giá trị khác biệt trung bình mẫu số giờ phát triển chuyên môn giáo viên theo hình thức trực tuyến ở các loại hình trường đều có giá trị $<0.050$, chứng tỏ có sự khác biệt về số giờ học trực tuyến ở các trường. Sự khác biệt này rõ rệt nhất là giữa trường công lập với trường quốc tế, số giờ trung bình giáo viên trường tư thục quốc tế dành cho phát triển chuyên môn hơn trường công lập là 17.68 giờ. Tiếp đến là sự chênh lệch giữa trường trường quốc tế với trường tư thục (với chương trình học thông thường) là 15.26 giờ, giữa trường tư thục quốc tế và trường tư thục song ngữ là 9.49 giờ. Thói quen phát triển chuyên môn giáo viên ít có sự chênh lệch nhất là giữa trường công lập và trường tư thục (với chương trình học thông thường), khác biệt giá trị trung bình giữa hai trường chỉ là 2.41 giờ. Giữa trường tư thục song ngữ với trường tư thục (với chương trình học thông thường) khác biệt thói quen phát triển chuyên môn giáo viên theo hình thức trực tuyến có cao hơn so với khác biệt giữa trường công lập với trường tư thục (với chương trình học thông thường) nhưng không nhiều, mức độ chênh lệch chỉ là 5.77 giờ. 
Ở hình thức phát triển chuyên môn giáo viên theo hình thức trực tiếp, các cặp giá trị $<0.05$ chỉ trừ cặp giá trị giữa trường công lập và trường tư thục (với chương trình học thông thường) có giá trị là $0.278>0.050$, nghĩa là có sự khác biệt thói quen phát triển chuyên môn của giáo viên theo hình thức trực tiếp ở các loại hình nhưng giữa trường công lập và trường tư thục (với chương trình học thông thường) là không có khác biệt. Giáo viên trường tư thục song ngữ có số giờ phát triển chuyên môn nhiều hơn trường tư thục (với chương trình học thông thường) và trường công lập lần lượt là 6,91 giờ và 9,59 giờ. Số giờ dành cho phát triển chuyên môn của giáo viên trường tư thục quốc tế nhiều hơn trường tư thục song ngữ, trường tư thục (với chương trình học thông thường) và trường công lập lần lượt là 5.68, 12.59 và 15.27 giờ.

Như vậy, có thể thấy, thói quen phát triển năng lực của giáo viên giữa các loại hình trường là không giống nhau. Mức độ khác biệt thói quen phát triển chuyên môn của giáo viên ở các loại hình trường thông qua hình thức trực tuyến cao hơn so với hình thức trực tiếp.

\section{Thảo luận}

Kết quả nghiên cứu cho thấy ở mỗi loại hình trường khác nhau, giáo viên có thói quen phát triển chuyên môn khác nhau. Tần suất các hoạt động phát triển chuyên môn giáo viên được ghi nhận nhiều nhất ở trường quốc tế, sau đó lần lượt giảm là trường tư thục song ngữ, trường tư thục (với chương trình học thông thường) và trường công lập. Điều này có thể là hệ quả của mô hình quản trị và chính sách riêng biệt của từng trường. Những đặc điểm này tương đồng với quan điểm từ nghiên cứu của Peretomode \& Dinzei (2019) và Babanoğlu và Yardımc1 (2017) về việc tham gia các chương trình hay các hoạt động phát triển chuyên môn giáo viên tại các trường công lập và tư thục. Mặc dù các giáo viên trường công lập có cơ hội để tham gia những chương trình phát triển chuyên môn nhưng cơ hội là không nhiều vì những đơn vị giáo dục công đa phần đều không tự chủ về tài chính. Việc này là rào cản tương đối lớn vì rất ít giáo viên chủ động tham gia các hoạt động phát triển chuyên môn bên ngoài không phải do nhà trường tổ chức vì khối lượng công việc của giáo viên khối phổ thông là tương đối nhiều và chưa kể đến nguồn thu nhập không cao. Giả sử các giáo viên trường công có cơ hội tiếp cận và tham gia những hoạt động nâng cao chuyên môn thì những hoạt động cũng không liên tục, ngắt quãng và manh mún. Nội dung các chương trình này có thể mới và thú vị nhưng lại khó để giáo viên ứng dụng với thực tế vì trường học công lập có thể gặp những ràng buộc nhất định. Hơn nữa, không phải tất cả các giáo viên trường công lập đều có cơ hội tham gia các chương trình phát triển chuyên môn giáo viên vì nhà trường có thể sẽ chỉ cử một vài giáo viên tiêu biểu đại diện tham gia các chương trình này. So với hệ thống giáo dục công lập, các trường học tư thục, bao gồm trường tư thục quốc tế, trường tư thục song ngữ và trường tư với chương trình học thông thường có sự đầu tư nhiều hơn cho các chương trình phát triển chuyên môn giáo viên. Trong nhóm các loại hình trường tư thục, giáo viên trường quốc tế có thói quen tham gia các hoạt động phát triển chuyên môn cao nhất. Đa phần, giáo viên trường quốc tế tham gia các hoạt động do nhà trường tài trợ. Trong khi đó, tỉ lệ tham gia các hoạt động phát triển chuyên môn không mất phí (không phải nhà truoờng tài trợ) và tự trả phí là thấp nhất. Kết quả Có thể thấy hệ thống giáo dục các trường học tư thục có sự quan tâm và đầu tư trong chính sách phát triển đội ngũ giáo viên nhiều hơn so với hệ thống giáo dục các trường học công lập. Điều này có thể được lí giải trong chính sự tự chủ tài chính, độc lập trong quản trị của các trường tư thục. Bên cạnh đó, chính từ sự đầu tư và quan tâm của nhà trường đối với việc phát triển chuyên môn nên chính giáo viên tại các hệ thống giáo dục tư thục luôn phải cập nhật, đổi mới bản thân cũng như ứng dụng những gì đã được tiếp cận từ những chương trình phát triển giáo viên đã được tham gia.

\section{Một số khuyến nghị}

Hiện tại, vẫn chưa có nhiều nghiên cứu về phát triển chuyên môn giáo viên ở Việt Nam. Hoạt động phát triển chuyên môn giáo viên nếu được xây dựng dựa trên các nghiên cứu, các bằng chứng khoa học sẽ hiệu quả, tối ưu và tránh lãng phí các nguồn lực. Chính bởi vậy, nghiên cứu phát triển chuyên môn phổ thông ở 
Việt Nam là đề tài cần được chú trọng nghiên cứu. Đó vừa là cơ hội vừa là trách nhiệm của những nhà nghiên cứu, nhà hoạt động giáo dục trong thời gian tới, đặc biệt với mục đích cải thiện thói quen tham gia, cũng như hiệu quả của cấc chương trình phát triển chuyên môn.

- Kết quả nghiên cứu là gợi ý cho các nhà hoạch định chính sách, các nhà quản lý giáo dục tại các cơ sở giáo dục phổ thông tham chiếu, xây dựng và điều chỉnh chính sách phát triển chuyên môn giáo viên và phát triển giáo dục bền vững.

- Việc xây dựng mô hình chính sách phát triển bền giáo dục bền vững cần được phát triển trên cơ sở nghiên cứu khoa học, phản biện và thực nghiệm về các hoạt động phát triển chuyên môn giáo viên.

- Nghiên cứu các tác động của chính sách từng loại hình trường học đối với các hoạt động phát triển chuyên môn giáo viên. Từ đó, trường học cũng như các nhà phát triển chương trình phát triển chuyên môn giáo viên có những thay đổi và điều chỉnh phù hợp với mỗi loại hình trường.

- Các chương trình phát triển chuyên môn giáo viên cần có sự tham gia của các bên liên quan như các nhà quản lí giáo dục, nhà nghiên cứu chính sách giáo dục, đơn vị đào tạo sư phạm, giáo viên và sinh viên các chương trình sư phạm.

- Nghiên cứu quan điểm của giáo viên trong từng loại hình trường học để đưa ra những chính sách phù hợp với điều kiện, môi trường làm việc của mỗi trường.

- Nghiên cứu về sự khác biệt trong thói quen phát triển chuyên môn của giáo viên cần được đào sâu và có thống kê chính thức để làm cơ sở cho việc phân tích sự khác biệt mô hình quản trị, quan điểm giáo dục cũng như chính sách của nhà trường có ảnh hưởng như thế nào đến phát triển chuyên môn của giáo viên.

- Kết quả nghiên cứu là gợi ý cho hệ thống giáo dục công lập chủ động xây dựng các chương trình phát triển chuyên môn; cả hệ thống giáo dục công lập và tư thục sắp xếp khối lượng công việc phù hợp để giáo viên được đảm bảo cả thời gian và sức khỏe cho công việc cũng như tham gia các hoạt động phát triển chuyên môn; mỗi loại hình trường học cần chọn lọc nội dung chương trình phát triển chuyên môn phù hợp với điều kiện riêng của mỗi trường để tránh lãng phí thời gian, chi phí cũng như có tính ứng dụng cao trong giảng dạy hàng ngày của giáo viên.

\section{Tài liệu tham khảo}

Abdal-Haqq, I. (1996). Making Time for Teacher Professional Development. ERIC Digest.

Akiba, M., \& Wilkinson, B. (2016). Adopting an international innovation for teacher professional development: State and district approaches to lesson study in Florida. Journal of Teacher Education, 67(1), 74-93.

Babanoğlu, M. P., \& YARDIMCI, A. (2017). Turkish State and Private School EFL Teachers' Perceptions on Professional Development. Çukurova University Faculty of Education Journal, 46(2).

Beijaard, D., Korthagen, F., \& Verloop, N. (2007). Understanding how teachers learn as a prerequisite for promoting teacher learning. Teachers and Teaching: Theory and Practice, 13, 105e108.

Bộ GD\&ĐT (2019). Giám đốc Ngân hàng thế giới tại Việt Nam: Chương trình ETEP có rất nhiều tiến bộ tích cực. http://icd.edu.vn/250/giam-doc-ngan-hang-the-gioi-tai-viet-nam-chuong-trinh-etep-corat-nhieu-tien-bo-tich-cuc.html

Bộ GD\&ĐT. (2019). Luật Giáo dục số 43/2019/QH14. Hà Nội. https://luatvietnam.vn/giao-duc/luat-giaoduc-2019-175003-d1.html

Broad, K., \& Evans, M. (2006). A review of literature on professional development content and delivery modes for experienced teachers. University of Toronto, Ontario Institute for Studies in Education.

Cochran-Smith, M., \& Lytle, S. L. (2001). Beyond certainty: Taking an inquiry stance on practice. Teachers caught in the action: Professional development that matters, 45-58. 
Corcoran, T. B. (1995). Helping Teachers Teach Well: Transforming Professional Development. CPRE Policy Briefs.

Cordingley, P., Bell, M., Thomason, S., \& Firth, A. (2005). The impact of collaborative continuing professional development (CPD) on classroom teaching and learning. Review: How do collaborative and sustained CPD and sustained but not collaborative CPD affect teaching and learning.

Choy, S. P. (1997). Public and private schools: How do they differ? (No. 12). Department of Education.

Dadds, M. (1997). Continuing professional development: nurturing the expert within. British Journal of Inservice Education, 23(1), 31-38.

Darling-Hammond, L., \& McLaughlin, M. W. (1995). Policies that support professional development in an era of reform. Phi delta kappan, 76(8), 597-604.

Darling-Hammond, L., Hyler, M. E., \& Gardner, M. (2017). Effective teacher professional development.

Day, C. (1999). Developing teachers: the challenges of lifelong learning (London, Routledge Falmer).

Desimone, L. M., \& Pak, K. (2017). Instructional coaching as high-quality professional development. Theory Into Practice, 56(1), 3-12.

Dronkers, J., \& Robert, P. (2003). The effectiveness of public and private schools from a comparative perspective.

Durksen, T. L., Klassen, R. M., \& Daniels, L. M. (2017). Motivation and collaboration: The keys to a developmental framework for teachers' professional learning. Teaching and teacher education, 67, 53-66.

Feiman-Nemser, S. (2001). From preparation to practice: Designing a continuum to strengthen and sustain teaching.

Forte, A. M., \& Flores, M. A. (2014). Teacher collaboration and professional development in the workplace: A study of Portuguese teachers. European Journal of Teacher Education, 37(1), 91-105.

Garet, M. S., Porter, A. C., Desimone, L., Birman, B. F., \& Yoon, K. S. (2001). What makes professional development effective? Results from a national sample of teachers. American educational research journal, 38(4), 915-945.

Geller, C. R., Sjoquist, D. L., \& Walker, M. B. (2006). The effect of private school competition on public school performance in Georgia. Public finance review, 34(1), 4-32.

Green, F., Machin, S., Murphy, R., \& Zhu, Y. (2008). Competition for private and state school teachers. Journal of Education and Work, 21(5), 383-404.

Hoàng, T. T., \& Ninh, T. H. (2017). Phát triển chương trình đào tạo, bồi dưỡng giáo viên đáp ứng yêu cầu đổi mới giáo dục phổ thông Việt Nam.

Hoang, A. D., Ta, N. T., Pham, H. H., Nguyen, Y. C., \& Luong, D. H. (2020). Survey on Teacher' Continuous Professional Development Habits in Vietnamese K-12 schools in 2019. Mendeley Data, V1. https://data.mendeley.com/datasets/s9by3yvh9t/1

Hoang, A. D., Pham, H. H., Nguyen, Y. C., Vuong, Q. H., Dam, M. Q., Tran, T., \& Nguyen, T. T. (2020). Introducing a tool to gauge curriculum quality under Sustainable Development Goal 4: The case of primary schools in Vietnam. International Review of Education, 1-29.

Hoang, Q. A. G. (2020). QUALITY ASSURANCE CHALLENGES: A study of quality assurance in private secondary education in Vietnam.

Hustler, D. (2003). Teachers' perceptions of continuing professional development.

Jaquith, A., Mindich, D., Wei, R. C., \& Darling-Hammond, L. (2010). Teacher Professional Learning in the United States: Case Studies of State Policies and Strategies. Summary Report. Learning Forward (NJ).

Imants, J., \& van Veen, K. (2010). Teacher learning as workplace learning. International encyclopedia of education, 7, 569-574.

Kagoda, A. M., \& Ezati, B. A. (2014). Secondary School Teachers' Perception of "Teacher Professional Development": A Case Study of Teachers from Five Districts of Uganda. Journal of Teacher Education and Educators, 3(2), 185-202. 
Kemp, M., \& Productions, R. (2009). Organisation for Economic Co-operation and Development.

Kennedy, A. (2014). Understanding continuing professional development: the need for theory to impact on policy and practice. Professional development in education, 40(5), 688-697.

Kieu, T. K., Singer, J., \& Gannon, T. J. (2016). Education for sustainable development in Vietnam: Lessons learned from teacher education. International Journal of Sustainability in Higher Education.

Lee, H. J. (2005). Developing a Professional Development Program Model Based on Teachers' Needs. Professional educator, 27, 39-49.

Le, T. Q., Bui, M. T., \& Phung, L. T. (2020). Application of Change Management Theory to Command New Teaching Activities in High Schools. International Journal of Innovation, Creativity and Change, 11(2), 557-568.

Lessing, A., \& De Witt, M. (2007). The value of continuous professional development: teachers' perceptions. South African journal of education, 27(1), 53-67.

Lộc, N. T. M. (2010). Đào tạo giáo viên chất lượng cao trong thời đại hiện nay. VNU Journal of Science: Social Sciences and Humanities, 26(1).

Louckes-Horsley, S., Love, N., Stiles, K. E., Mundrey, S., \& Hewson, P. (1998). Designing professional development for teachers of science and mathematics.

MCLAUGHLIN, M. W. (2001). Trajectories of Teachers' Inquiry, Analysis, and Action. Teachers caught in the action: Professional development that matters, 31, 79.

Minh, H. (2020, June 23). Intel hỗ trợ đào tạo 78,000 giáo viên, sinh viên. Vietnam+ https://www.vietnamplus.vn/intel-ho-tro-dao-tao-78000-giao-vien-sinh-vien/72107.vnp

Nghia, T. L. H., \& Tai, H. N. (2017). Preservice Teachers' Identity Development during the Teaching Internship. Australian Journal of Teacher Education, 42(8), 1-15.

Nyunt, N. S., \& Ye, Y. (2019). The Relationship Study of Teachers' Perceptions Towards Professional Development and Their Job Satisfaction at Monastic Primary School in Namlan, Hsipaw, Northern Shan State, Myanmar. Scholar: Human Sciences, 11(1), 1.

OECD (1998). Staying ahead: in-service training and teacher professional development. OECD Publishing.

OECD (2012). Public and Private Schools: How Management and Funding Relate to their Socio-economic Profile. OECD Publishing.

OECD (2013). Strong performers and successful reformers in education: lessons from PISA 2012 for the United States. OECD, Paris, France.

Peretomode, V. F., \& Dinzei, M. M. (2019). Professional development needs of public and private secondary school principals in Delta State, Nigeria. International Journal of Educational Administration, 11(1), 7-21.

Postholm, M. B. (2012). Teachers' professional development: a theoretical review. Educational research, 54(4), 405-429.

Ryan, R. M., \& Deci, E. L. (2000). Intrinsic and extrinsic motivations: Classic definitions and new directions. Contemporary educational psychology, 25(1), 54-67.Scribner, Jay Paredes. "Professional development: Untangling the influence of work context on teacher learning." Educational Administration Quarterly 35.2 (1999): 238-266.

Scotchmer, M. (2005). Characteristics of public school teachers' professional development activities: 1999-2000. National Center for Education Statistics, US Department of Education, Institute of Education Sciences.

Scribner, J. P. (1999). Professional development: Untangling the influence of work context on teacher learning. Educational Administration Quarterly, 35(2), 238-266.

Sellen, P. (2016). Teacher workload and professional development in England's secondary schools: insights from TALIS. Education policy institute.

Shimahara, N. K. (1998). The Japanese model of professional development: Teaching as craft. Teaching and teacher education, 14(5), 451-462. 
Shallcross, T., O'Loan, K., \& Hui, D. (2000). Developing a school focused approach to continuing professional development in sustainability education. Environmental Education Research, 6(4), 363-382.

Sparks, D., \& Hirsh, S. (2000). A national plan for improving professional development.

Sparks, D., \& Loucks-Horsley, S. (1990). Models of staff development. Handbook of research on teacher education, 3, 234-250.

Stabback, P. (2016). What Makes a Quality Curriculum? In-Progress Reflection No. 2 on" Current and Critical Issues in Curriculum and Learning". UNESCO International Bureau of Education.

Tamhane, A. C. (1977). Multiple comparisons in model I one-way ANOVA with unequal variances. Communications in Statistics-Theory and Methods, 6(1), 15-32.

Tooley, J., \& Longfield, D. (2015). Countries: A response to the DFID-commissioned" Rigorous Literature Review". London: Pearson, 2015.

Tuyet, T. T. (2017). BỒI DƯƠNG GIÁO VIÊN VÀ YÊU CẦU QUAN TÂM TỚI KINH NGHIỆM VÀ ĐẶC ĐIỂM MÔI TRƯỜNG GIẢNG DẠY CỦA NGƯỜI ĐƯợC BỒI DƯỠNG. VNU Journal of Foreign Studies, 33(5).

Urquiola, M. (2016). Competition among schools: Traditional public and private schools. In Handbook of the Economics of Education (Vol. 5, pp. 209-237). Elsevier.

Villegas-Reimers, E. (2003). Teacher professional development: an international review of the literature. Paris: International Institute for Educational Planning

Walker, A. (1996). Professional development in Hong Kong primary schools: beliefs, practices and change. Journal of Education for Teaching, 22(2), 197-212.

Webster-Wright, A. (2009). Reframing professional development through understanding authentic professional learning. Review of educational research, 79(2), 702-739.

Yip, E. T. M. (1998). Teachers' perceptions of professional development (Doctoral dissertation). 


\section{PHỤ LỤC}

Phu lục 1: Thống kê mô tả số giờ học của giáo viên ở các loại hình trường

\begin{tabular}{|c|c|c|c|c|c|c|c|c|c|}
\hline \multirow{2}{*}{\multicolumn{2}{|c|}{ Loại hình }} & \multirow{2}{*}{$\begin{array}{l}\text { Số } \\
\text { lượng }\end{array}$} & \multirow{2}{*}{$\begin{array}{c}\text { Giá } \\
\text { trị } \\
\text { trung } \\
\text { bình }\end{array}$} & \multirow{2}{*}{$\begin{array}{c}\text { Độ } \\
\text { lệch } \\
\text { chuẩn }\end{array}$} & \multirow{2}{*}{$\begin{array}{c}\text { Sai } \\
\text { số } \\
\text { chuẩn }\end{array}$} & \multicolumn{2}{|c|}{$\begin{array}{c}\text { Khoảng tin cậy } \\
95 \%\end{array}$} & \multirow{2}{*}{$\begin{array}{c}\text { Giá } \\
\text { trị } \\
\text { nhỏ } \\
\text { nhất }\end{array}$} & \multirow{2}{*}{$\begin{array}{c}\text { Giá } \\
\text { trị } \\
\text { lớn } \\
\text { nhất }\end{array}$} \\
\hline & & & & & & $\begin{array}{l}\text { Giới } \\
\text { hạn } \\
\text { dưới }\end{array}$ & $\begin{array}{c}\text { Giởi } \\
\text { hạn trên }\end{array}$ & & \\
\hline \multirow{5}{*}{$\begin{array}{l}\text { Trực } \\
\text { tuyến }\end{array}$} & Công lập & 138 & 5.01 & 3.64 & 0.31 & 4.39 & 5.62 & 0 & 14 \\
\hline & $\begin{array}{l}\text { Tư thục (CT thông } \\
\text { thường) }\end{array}$ & 145 & 7.42 & 6.18 & 0.51 & 6.41 & 8.43 & 0 & 28 \\
\hline & Tư thục song ngữ & 140 & 13.19 & 5.31 & 0.49 & 12.31 & 14.08 & 4 & 32 \\
\hline & Tư thục quốc tế & 41 & 22.68 & 8.1 & 1.27 & 20.13 & 25.24 & 9 & 44 \\
\hline & Tổng số & 464 & 9.79 & 7.53 & 0.35 & 9.11 & 10.48 & 0 & 44 \\
\hline \multirow{5}{*}{$\begin{array}{l}\text { Trực } \\
\text { tiếp }\end{array}$} & Công lập & 138 & 43.12 & 12.56 & 1.07 & 41 & 45.23 & 20 & 74 \\
\hline & $\begin{array}{l}\text { Tư thục (CT thông } \\
\text { thường) }\end{array}$ & 145 & 45.8 & 10.5 & 0.87 & 44.08 & 47.52 & 24 & 76 \\
\hline & Tư thục song ngữ & 140 & 52.71 & 7.11 & 0.6 & 51.52 & 53.9 & 34 & 72 \\
\hline & Tư thục quốc tế & 41 & 58.39 & 7.96 & 1.24 & 55.88 & 60.9 & 41 & 82 \\
\hline & Tổng số & 464 & 48.2 & 11.25 & 0.52 & 47.17 & 49.22 & 20 & 82 \\
\hline
\end{tabular}


Phu lục 2: So sánh sụ khác biệt số giờ học của giáo viên giũa các loại hình truờng

\begin{tabular}{|c|c|c|c|c|c|c|c|}
\hline \multirow{2}{*}{$\begin{array}{l}\text { Biến } \\
\text { phụ } \\
\text { thuộc }\end{array}$} & \multirow{2}{*}{$\begin{array}{l}\text { (I) Loại hình trường } \\
\text { 1. Công lập } \\
\text { 2. Tư thục (CT thông } \\
\text { thường) } \\
\text { 3. Tư thục song ngữ } \\
\text { 4. Tư thục quốc tê }\end{array}$} & \multirow{2}{*}{$\begin{array}{l}\text { (J) Loại hình trường } \\
\text { 1. Công lập } \\
\text { 2. Tư thục (CT thông } \\
\text { thường) } \\
\text { 3. Tư thục song ngữ } \\
\text { 4. Tư thục quốc tể }\end{array}$} & \multirow{2}{*}{$\begin{array}{l}\text { Khác } \\
\text { biệt } \\
\text { trung } \\
\text { bình } \\
\text { mẫu } \\
(\mathrm{I}-\mathrm{J})\end{array}$} & \multirow{2}{*}{$\begin{array}{c}\text { Sai } \\
\text { số } \\
\text { chuẩn }\end{array}$} & \multirow{2}{*}{ Trị số } & \multicolumn{2}{|c|}{$\begin{array}{c}\text { Khoảng tin cậy } \\
\qquad 95 \%\end{array}$} \\
\hline & & & & & & $\begin{array}{l}\text { Giới } \\
\text { hạn } \\
\text { dưới }\end{array}$ & $\begin{array}{l}\text { Giới } \\
\text { hạn } \\
\text { trên }\end{array}$ \\
\hline \multirow{12}{*}{$\begin{array}{l}\text { Trực } \\
\text { tuyêfn }\end{array}$} & \multirow{3}{*}{1} & 2 & $-2.41+$ & 0.6 & 0.000 & -4 & -0.82 \\
\hline & & 3 & -8.19 & 0.55 & 0.000 & -9.63 & -6.74 \\
\hline & & 4 & -17.68 & 1.3 & 0.000 & -21.26 & -14.09 \\
\hline & \multirow{3}{*}{2} & 1 & $2.41^{+}$ & 0.6 & 0.000 & 0.82 & 4 \\
\hline & & 3 & -5.77 & 0.68 & 0.000 & -7.58 & -3.97 \\
\hline & & 4 & -15.26 & 1.37 & 0.000 & -18.99 & -11.53 \\
\hline & \multirow{3}{*}{3} & 1 & 8.19 & 0.55 & 0.000 & 6.74 & 9.63 \\
\hline & & 2 & $5.77^{+}$ & 0.68 & 0.000 & 3.97 & 7.58 \\
\hline & & 4 & -9.49 & 1.34 & 0.000 & -13.16 & -5.82 \\
\hline & \multirow{3}{*}{4} & 1 & 17.68 & 1.3 & 0.000 & 14.09 & 21.26 \\
\hline & & 2 & 15.26 & 1.37 & 0.000 & 11.53 & 18.99 \\
\hline & & 3 & 9.49 & 1.34 & 0.000 & 5.82 & 13.16 \\
\hline \multirow{12}{*}{$\begin{array}{l}\text { Trực } \\
\text { tiếp }\end{array}$} & \multirow{3}{*}{1} & 2 & -2.68 & 1.38 & 0.278 & -6.34 & 0.97 \\
\hline & & 3 & -9.59 & 1.27 & 0.000 & -12.85 & -6.33 \\
\hline & & 4 & -15.27 & 1.64 & 0.000 & -19.67 & -10.88 \\
\hline & \multirow{3}{*}{2} & 1 & 2.68 & 1.38 & 0.278 & -0.97 & 6.34 \\
\hline & & 3 & -6.91 & 1.06 & 0.000 & -9.72 & -4.1 \\
\hline & & 4 & -12.59 & 1.52 & 0.000 & -16.68 & -8.5 \\
\hline & \multirow{3}{*}{3} & 1 & 9.59 & 1.23 & 0.000 & 6.33 & 12.85 \\
\hline & & 2 & $6.91^{+}$ & 1.06 & 0.000 & 4.1 & 9.72 \\
\hline & & 4 & -5.68 & 1.38 & 0.001 & -9.44 & -1.93 \\
\hline & \multirow{3}{*}{4} & 1 & $15.27^{+}$ & 1.64 & 0.000 & 10.88 & 19.67 \\
\hline & & 2 & 12.59 & 1.52 & 0.000 & 8.5 & 16.68 \\
\hline & & 3 & 5.68 & 1.38 & 0.001 & 1.93 & 9.44 \\
\hline
\end{tabular}

* Khác biệt trung bình mẫu có ý nghĩa ở khoảng tin cậy $95 \%$ 
Dữ liệu trong nghiên cứu này được trích xuất từ bảng hỏi về thói quen phát triển chuyên môn của giáo viên tại các nước Đông Nam Á. Dưới đây là toàn văn bảng hỏi gốc bằng tiếng Anh.

\section{Teacher Continuing Professional Development in K-12 education in Vietnam - An Exploratory survey}

\section{A. Demographics Information}

1. In which country are you teaching?

- Brunei Darussalam

- Cambodia

- Indonesia

- Lao PDR $\square$ Malaysia

Myanmar

$\square$ Philippines

Singapore
Thailand

Timor Leste

Vietnam

2. What is your nationality?

- Brunei Darussalam

- Cambodia

- Indonesia

- Lao PDR

- Malaysia

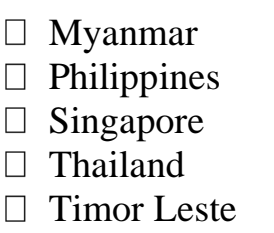

Vietnam

America

Australia and New Zealand

Europe

Other

3. What kind of school are you working at?

- Public school

- Private - normal school

- Private - bilingual school (50\% of subjects are taught by English)

- Private - International school (100\% of subjects are taught by English)

4. What kind of curriculum are you teaching?

- National Curriculum

- Extended from national curriculum

- IB

- Cambridge

5. Which grades are you teaching?
- $1 \quad 1 \quad \square 5 \quad \square 9$
- $2 \square 6 \quad \square 10$
- $3 \square 7 \square 11$
- $4 \quad \square 8 \quad \square 12$

6. What subjects are you teaching?
- English
Literature
IT
- Math
Social Sciences
Music
- Sciences
Mother language
Arts 
7. Your gender

- Male

- Female

8. How many years of teaching experience do you have (in total)?

- Less than 3

- Less than 5

- Less than 10

- More than 10

9. How many years of teaching experience at the current school do you have?

- Less than 3

- Less than 5

- Less than 10

- More than 10

10. How many countries have you ever taught?

11. Your English proficiency level?

- Beginning

- Intermediate/ B1 or equivalent

- Upper Intermediate/ B2 or equivalent

- Advanced/ $\mathrm{C} 1$ or equivalent

- Proficient/ C2 or equivalent

- Native speaker

12. What education degree(s) do you have?

- BA in Edu $\quad \square$ BA other

- MA in Edu $\square$ MA in other

- Dr in Edu $\square$ Dr in other

\section{B. Continuing Professional Development Habit}

13. For the last 12 months, how many hours of courses/workshops/seminars have you attended?

[Number]

14. Among all of the activities you have attended for the last 12 months, how many hours of the activities are...

- Online courses (self-pace): [Number]

- Online course (interactive): [Number] 
- Online webinar: [Number]

- Offline courses (being taught): [Number]

- Offline workshops (interactive activities): [Number]

- Offline seminars/conferences: [Number]

15. How many activities were financed by..

- By your own money: [Number]

- School's support: [Number]

- The activities are free: [Number]

- Government's scholarship: [Number]

- Business' scholarship/sponsorship: [Number]

- NGO' scholarship/sponsorship: [Number]

- Friend's support: [Number]

16. After attending those activities, how often do you share the knowledge forward for other colleagues? $(1=$ Strongly disagree; $2=$ Disagree; $3=$ Neither agree/disagree; $4=$ Agree $; 5=$ Strongly agree $)$

\begin{tabular}{|l|l|l|l|l|l|}
\hline & $\mathbf{1}$ & $\mathbf{2}$ & $\mathbf{3}$ & $\mathbf{4}$ & $\mathbf{5}$ \\
\hline 16.1. Right after the attendance & 1 & 2 & 3 & 4 & 5 \\
\hline 16.2 A week after the attendance & 1 & 2 & 3 & 4 & 5 \\
\hline 16.3 A month after the attendance & 1 & 2 & 3 & 4 & 5 \\
\hline 16.4 Two months after the attendance & 1 & 2 & 3 & 4 & 5 \\
\hline 16.5 Never share anything learned & 1 & 2 & 3 & 4 & 5 \\
\hline
\end{tabular}

17. What is your motivation toward those professional development activities ( 1 = Strongly disagree; 2 = Disagree; $3=$ Neither agree/disagree $; 4=$ Agree $; 5=$ Strongly agree $)$

\begin{tabular}{|l|l|l|l|l|l|}
\hline & $\mathbf{1}$ & $\mathbf{2}$ & $\mathbf{3}$ & $\mathbf{4}$ & $\mathbf{5}$ \\
\hline 17.1 To enhance my overall knowledge & 1 & 2 & 3 & 4 & 5 \\
\hline 17.2 To enhance my domain knowledge & 1 & 2 & 3 & 4 & 5 \\
\hline 17.3 To get promotion & 1 & 2 & 3 & 4 & 5 \\
\hline 17.4 To have better pedagogical skills & 1 & 2 & 3 & 4 & 5 \\
\hline 17.5 To have better technical skills & 1 & 2 & 3 & 4 & 5 \\
\hline 17.6 To fulfill the requirement of my school/school district & 1 & 2 & 3 & 4 & 5 \\
\hline 17.7 Encouraged by my colleagues & 1 & 2 & 3 & 4 & 5 \\
\hline 17.8 Encouraged by my leaders & 1 & 2 & 3 & 4 & 5 \\
\hline
\end{tabular}

\section{Teacher's experience and perception of Project-based and Problem-based learning (PBLs)}

18. How many hours of training/learning on Project-based Learning do you have?

[Number]

19. In PBLs, a driving question is a must-have? 
$(1=$ Strongly disagree; $2=$ Disagree $; 3=$ Neither agree $/$ disagree $; 4=$ Agree $; 5=$ Strongly agree $)$

20. How detail should a driving question be?

(1 - Very General, 5 - Very Detail)

21. Regarding your opinion, educational approaches should be student-centric or teacher-centric? (1- Teacher-centric, 10 - Student-centric)

22. Without the teacher's instruction, students will not be able to acquire the learning outcomes? ( 1 = Strongly disagree; 2 = Disagree; $3=$ Neither agree $/$ disagree $; 4=$ Agree $; 5=$ Strongly agree $)$

23. A driving question formed by students cannot reach the learning targets?

( 1 = Strongly disagree; 2 = Disagree; 3 = Neither agree/disagree; 4 = Agree; 5 = Strongly agree $)$

24. What are the challenges for teachers to form driving questions?

( 1 = Strongly disagree; 2 = Disagree; 3 = Neither agree/disagree; 4 = Agree; 5 = Strongly agree $)$

\begin{tabular}{|l|l|l|l|l|l|}
\hline & $\mathbf{1}$ & $\mathbf{2}$ & $\mathbf{3}$ & $\mathbf{4}$ & $\mathbf{5}$ \\
\hline 24.1 Time-consuming (before the lesson) & 1 & 2 & 3 & 4 & 5 \\
\hline 24.2 Time-consuming (during the lesson) & 1 & 2 & 3 & 4 & 5 \\
\hline 24.3 Adjust the questions to fit all students & 1 & 2 & 3 & 4 & 5 \\
\hline
\end{tabular}

25. What are the challenges for students to form driving questions?

( 1 = Strongly disagree; 2 = Disagree; 3 = Neither agree/disagree; 4 = Agree; $5=$ Strongly agree $)$

\begin{tabular}{|l|l|l|l|l|l|}
\hline & $\mathbf{1}$ & $\mathbf{2}$ & $\mathbf{3}$ & $\mathbf{4}$ & $\mathbf{5}$ \\
\hline 25.1 Weak decision-making skills & 1 & 2 & 3 & 4 & 5 \\
\hline 25.2 Lack of know-how about the big picture & 1 & 2 & 3 & 4 & 5 \\
\hline 25.3 Time-consuming (before the lesson) & 1 & 2 & 3 & 4 & 5 \\
\hline 25.4 Time-consuming (during the lesson) & 1 & 2 & 3 & 4 & 5 \\
\hline 25.5 Lack of proactive learning habit & 1 & 2 & 3 & 4 & 5 \\
\hline 25.6 Difficult to reach alignment & 1 & 2 & 3 & 4 & 5 \\
\hline
\end{tabular}

26. A driving question can be formed by teachers only

( 1 = Strongly disagree; 2 = Disagree; $3=$ Neither agree/disagree $; 4=$ Agree $; 5=$ Strongly agree $)$

27. A driving question can be formed by students only 
$(1=$ Strongly disagree; 2 = Disagree $; 3=$ Neither agree $/$ disagree $; 4=$ Agree $; 5=$ Strongly agree $)$

28. A driving question can be formed by both teachers and students

( 1 = Strongly disagree; 2 = Disagree; 3 = Neither agree $/$ disagree $; 4$ = Agree $; 5$ = Strongly agree $)$

29. You are willing to let your students decide their learning pathway?

( 1 = Strongly disagree; 2 = Disagree; 3 = Neither agree/disagree; 4 = Agree; 5 = Strongly agree $)$

30. You are willing to let your students form the driving questions?

( 1 = Strongly disagree; 2 = Disagree; 3 = Neither agree $/$ disagree $; 4$ = Agree; 5 = Strongly agree $)$

31. In your PBLs class, the lesson often starts with...

( 1 = Strongly disagree; 2 = Disagree $; 3$ = Neither agree/disagree; 4 = Agree; 5 = Strongly agree $)$

\begin{tabular}{|l|l|l|l|l|l|}
\hline & $\mathbf{1}$ & $\mathbf{2}$ & $\mathbf{3}$ & $\mathbf{4}$ & $\mathbf{5}$ \\
\hline 31.1 A driving question provided by me & 1 & 2 & 3 & 4 & 5 \\
\hline 31.2 A list of driving questions provided by me & 1 & 2 & 3 & 4 & 5 \\
\hline 31.3 A driving question provided by students & 1 & 2 & 3 & 4 & 5 \\
\hline
\end{tabular}

32. In your PBLs class, the driving questions are generated...

\begin{tabular}{|l|l|l|l|l|l|}
\hline & $\mathbf{1}$ & $\mathbf{2}$ & $\mathbf{3}$ & $\mathbf{4}$ & $\mathbf{5}$ \\
\hline 32.1 after brainstorming/discussion sessions & 1 & 2 & 3 & 4 & 5 \\
\hline 32.2 to follow previous discussions & 1 & 2 & 3 & 4 & 5 \\
\hline
\end{tabular}

33. At your school, on average, a teacher has to cover how many students?

[Number]

Thank you so much for your participation! 